\title{
Профилактика травматизма спортсменов, специализирующихся в теннисе, посредством использования стретч-упражнений
}

\author{
'О. Е. Афтимичук, ${ }^{2}$ А. И. Лукин
}

\author{
1Государственный университет физического воспитания и спорта Республики \\ Молдова, Кишинев, Молдова \\ 2ГБОУ ВПО РНИМУ им. Н.И. Пирогова Минздрава России, Москва, Россия
}

\begin{abstract}
Резюме. У роботі представлено матеріали дослідження проблеми спортивного травматизму у тенісі. Вивчено можливості засобів стретчингу у профілактиці отримання травм тенісистами. Експериментальна методика включає використання стретч-вправ у підготовчій і заключній частинах тренувального заняття. Апробовано методи активного динамічного стретчингу та агоністичного стретчингу. Використовувалися стретч-вправи, що виконуються в режимі утримання максимальної амплітуди в різних положеннях партеру. У результаті впровадження стретчингової програми у тренувальний процес кількість травм у тенісистів скоротилася на $21,1 \%$

Ключові слова: теніс, травматизм, стретчинг.
\end{abstract}

Summary. This paper presents information on the study of the problem of sports injuries in tennis. The authors have explored means of stretching in the prevention of injury tennis players.

The experimental procedure involved the use of stretch exercises in the preparatory and final parts of the training session. Were tested methods of active dynamic stretching, stretching method agonist used stretch exercises performed on hold maximum amplitude in different positions of parterre. As a result of the implementation of the program of stretching in the training process of the number of injuries in tennis players fell by $21.1 \%$.

Key words: tennis, injuries, stretching.

Постановка проблемы. Общепризнано, что наибольшие возможности активизации резервов организма для повышения специальной работоспособности заключаются в совершенствовании средств и методов тренировки, режимов работы и восстановления, рациональных сочетаний тренировочных нагрузок разной направленности. Наряду с этим для повышения эфффективности направленных тренировочных воздействий на организм широко используются неспецифичееские вспомогательные средства, которые готовят спортсмена к предстоящим нагрузкам или стимулируют и поддерживают на необходимом уровне реакции организма в ходе тренировочных занятий или соревнований и ускоряют восстановительные процессы [2, 3]. Цель таких воздействий - создание условий для восстановления способности к максимальной (или оптимальной) реализации имеющегося у спортсмена двигательного потенциала. Таким образом можно создать предпосылки для повышения тренировочного эфффекта нагрузок при интенсификации тренировочного процесса и для более полной реализации потенциала спортсмена в соревновательной деятельности.
В настоящее время спортивной наукой и передовой практикой достаточно обосновано аргументирование проблемы подготовки организма к высоким нагрузкам и восстановлению.

Установлено, что основной задачей всех средств - подготовки и восстановления - является аксиома: содействовать естественному течению фризиологических процессов организма тренирующегося спортсмена. Это может иметь педагогический, психологический или медикобиологический эффект.

Между тем, разнообразие фризических упражнений и нагрузок затрудняет нахождение универсальных критериев, определяющих степень подготовленности организма к нагрузкам и восстановлению.

Анализ последних исследований и публикаций. Известно, что способность мышц к растягиванию, а также фризиологические процессы, происходящие при этом, сегодня берутся за основу для решения трех важнейших задач спортивной тренировки $[1,4,5,8,10]:$ развития гибкости; предварительной подготовки мышц к фризическим нагрузкам (т. е. для разминки с целью профрилактики травматизма); восстановления 
фризиологических фрункций после больших тренировочных нагрузок.

До последнего времени основными видами упражнений для решения вышеуказанных задач были динамические упражнения баллистического характера: маховые движения руками и ногами, сгибания и разгибания туловища, обычно выполняемые с большой амплитудой и значительной скоростью. Здесь удлинение определенной группы мышц оказывается сравнительно кратковременным - длится столько, сколько длятся мах и сгибание. Скорость растягивания мышц обычно пропорциональна скорости махов и сгибаний. Однако чрезмерные растяжения за счет рывковых движений могут создать микроскопические разрывы в мышцах, что, в свою очередь, приводит к образованию в мышцах рубцовой ткани (мышцы становятся жесткими), постепенному уменьшению эластичности и болезненным ощущениям $[2,7,9]$.

С целью более профессионального подхода к упражнениям на растягивание предлагается использовать стретчинг. В настоящее время среди спортсменов такая форма подготовки мышечносвязочного аппарата к тренировочным и соревновательным нагрузкам чрезвычайно популярна, а в качестве формы активного отдыха стретчинг применяется для восстановления.

Таким упражнениям на растягивание посвящено немало работ, однако на многие вопросы еще нет точного ответа. Поэтому поиск наиболее эфрфективного применения стретчинга в спортивной деятельности высококвалифицированных спортсменов сегодня очень актуален.

В соответствии со сложившимися представлениями наиболее распространенной установкой использования стретч-упражнений является подготовка организма к нагрузкам, коррекция состояния утомления и ускорения процессов восстановления [6].

Цель стретчинга - определить уровень функциональной нагрузки стретч-упражнений в структуре тренировочного процесса для профиллактики спортивного травматизма теннисистов.

В исследовании были использованы такие методы: теоретический анализ и обобщение данных специализированной научной и методической литературы; анализ учебно-тренировочного процесса в теннисе и материалов врачебного контроля; тестирование; эксперимент; математическая статистика.

Исследование проводилось на базе Некоммерческого образовательного учреждения Высшая Школа Теннисного Мастерства «Янтарь» (Москва, Россия). Продолжительность исследования ох- ватывала одиннадцать месяцев, участие принимали теннисисты учебно-тренировочной группы в возрасте 15-16 лет (15 человек) на этапе совершенствования спортивного мастерства. В рамках педагогического эксперимента в систему тренировочных занятий была внедрена разработанная методика применения стретч-упражнений с целью профилактики травматизма у теннисистов.

Результаты исследования и их обсуждение. Повышение уровня учебно-тренировочного процесса теннисистов возможно лишь при условии постоянного интереса к новым методикам и фрормам организации занятий. Обогащение новой информацией, стремление к творчеству, разработка новых методик с использованием разнообразных средств должны повысить эфрфрективность учебно-тренировочных занятий.

Изучение опыта работы тренеров тенниса, анализ их практической документации (планирование циклов тренировочных занятий, рабочие записи текущих занятий) позволили установить, что тренировочные программы располагают достаточным арсеналом средств и методов их использования. Однако на практике обходятся очень скудным, хотя и традиционным, составом средств.

Материалы врачебного контроля теннисистов позволили выявить характер травм и условия их получения. Однако проблема профилактики травматизма остается открытой для учебнотренировочного процесса в теннисе, поскольку условия ее реализации не отражены ни в документации тренеров и спортсменов, ни в практической (тренировочной) деятельности.

Известно, что упражнения на растягивание способствуют развитию большей амплитуды, а также формируют двигательную свободу, что отражается на воспитании координации. Все это в целом содействует оптимальной технике выполнения двигательных действий теннисистов, а значит, и снижению уровня травматизма в тренировочно-соревновательный период.

Разработанная нами экспериментальная методика включала использование стретч-упражнений в подготовительной и заключительной частях тренировочного занятия теннисистов, а основная была направлена на отработку двигательных действий и учебных игр.

Подготовительная часть учебно-тренировочного занятия длилась 20-30 мин в зависимости от поставленных перед тренировкой задач, что согласовывалось с периодами макроцикла спортивной подготовки теннисистов. Более продолжительное время (25-30 мин) отводилось на подготовительный и переходной периоды макроцикла. 
Разминка состояла из трех частей: варианты ходьбы и бега, комплекс аэробных упражнений, стретч-упражнения.

Комплекс аэробных упражнений и стретчинга выполнялся под музыкальное сопровождение, которое обеспечивало аэробные условия для первой группы упражнений и условия, соответствующие характеру второй группы упражнений, а также помогало стимулировать занимающихся к предстоящей работе в основной части занятия.

Стретч-упражнения выполнялись из положения стоя в динамическом режиме. Растягиванию подвергались все суставы, а также мышечные группы, на которые приходилась базовая нагрузка в основной части тренировки. Здесь был использован метод активного динамического стретчинга с чередованием мышц-антагонистов. Техника исполнения стретч-упражнений заключалась в принятии позы, определяющей мышечную группу или суставы для растягивания, и дальнейших амортизационных движений небольшой амплитуды.

Комплекс стретч-упражнений предусматривал «растяжки» мышц шеи и лучезапястных суставов методом агонистического стретчинга.

Заключительная часть тренировки полностью состояла из стретч-упражнений, дополняющихся упражнениями на дыхание. Выполнялся глубокий стретчинг в разных положениях партера в режиме удержания максимальной амплитуды.

В отличие от подготовительной части, стретчупражнения заключительной части занятия определялись фриксацией принятой позы от 20 до 30 с, для чего использовались асаны хатка-йоги. Некоторые упражнения выполнялись в анаэробном режиме с задержкой дыхания на вдохе и выдохе. В основном это касалось упражнений на скручивание туловища и принятия положений тела согнувшись.

В заключение выполнялись релаксационные упражнения, которые также не исключали "растяжек» и упражнений на дыхание.

Положительный эфффект внедрения стретч-упражнений в учебнотренировочный процесс представлен в таблице 1.

Тестированию были подвергнуты различные отделы позвоночника и суставы верхних и нижних конечностей, участвующих в двигательных актах теннисистов. Все конечные показатели гибкости теннисистов представлены положительными ре- зультатами. Это подтверждается математическими данными исследованных параметров гибкости. Из 11 проанализированных параметров два показали уровень статистической достоверности $\mathrm{p}<$ 0,001: гибкость позвоночника при наклоне туловища влево $(\mathrm{t}=5,383)$ и правого тазобедренного сустава $(t=4,763)$. Данные первого из представленных параметров можно объяснить спецификой вида спорта, где базовым элементом техники является широкий амплитудный замах, включающий не только область руки, но и соответствующую ей сторону туловища. Другой параметр определяет работу ног на прием мяча при выполнении выпадов.

Пять параметров продемонстрировали уровень достоверности исходных и конечных данных при $p<0,01$. Здесь можно обратить внимание, что три из них представляют правую сторону тела спортсмена, что можно отнести, по нашему мнению, к праворукости теннисистов, участвовавших в эксперименте, а также два показателя при наклоне вперед, как головы, так и туловища.

Остальные четыре параметра выявили статистическую достоверность на уровне $p<0,05$ и представлены левой стороной тела и наклоном головы назад, что не снижает достоинств стретч-программы для фризической подготовленности спортсменов.

Эффрективность разработанной методики можно оценить по количеству полученных травм теннисистами до введения экспериментальной программы по стретчингу в систему тренировочных занятий и после ее апробации.

По данным медицинского контроля и опросу спортсменов было выявлено, что за период учебно-тренировочного года состав травм

ТАБЛИЦА 1 - Динамика среднегрупповых показателей развития гибкости у теннисистов $(\bar{x} \pm \mathrm{m})$ *

\begin{tabular}{|l|l|c|c|c|c|}
\hline \multirow{2}{*}{$\begin{array}{l}\text { Область иссле- } \\
\text { дования }\end{array}$} & \multirow{2}{*}{$\begin{array}{l}\text { Направление } \\
\text { движения }\end{array}$} & \multicolumn{2}{|c|}{ Показатель гибкости, см } & \multirow{2}{*}{$\mathbf{t}$} & р \\
\cline { 3 - 4 } $\begin{array}{l}\text { Шейный отдел } \\
\text { позвоночника }\end{array}$ & Вправо & Всходный & конечный & & \\
при наклоне & Влево & $2,08 \pm 0,58$ & $4,0 \pm 0,67$ & 3,249 & $<0,01$ \\
головы & Вперед & $2,17 \pm 0,58$ & $4,0 \pm 0,58$ & 3,261 & $<0,01$ \\
& Назад & $10,75 \pm 0,93$ & $12,92 \pm 0,84$ & 2,380 & $<0,05$ \\
\hline Плечевой & Правый & $26,08 \pm 1,45$ & $20,89 \pm 1,23$ & 3,961 & $<0,01$ \\
сустав & Левый & $28,12 \pm 1,57$ & $24,08 \pm 1,32$ & 2,855 & $<0,05$ \\
\hline Позвоночник & Вправо & $8,42 \pm 0,75$ & $12,93 \pm 1,03$ & 3,632 & $<0,01$ \\
при наклоне & Влево & $8,58 \pm 0,75$ & $13,25 \pm 1,03$ & 5,383 & $<0,001$ \\
туловища & Вперед & $2,65 \pm 1,17$ & $7,67 \pm 1,38$ & 4,025 & $<0,01$ \\
\hline Тазобедренный & Правый & $15,58 \pm 1,68$ & $8,42 \pm 1,38$ & 4,763 & $<0,001$ \\
сустав & Левый & $14,33 \pm 1,59$ & $10,42 \pm 1,41$ & 2,768 & $<0,05$ \\
\hline
\end{tabular}

${ }^{\star} \mathrm{n}=15(\mathrm{f}=14)$ при $\mathrm{p}<0,05, \mathrm{t}=2,145 ; \mathrm{p}<0,01, \mathrm{t}=2,977 ; \mathrm{p}<0,001, \mathrm{t}=4,140$ 
ТАБЛИЦА 2 - Среднегрупповые данные по травмам у теннисистов, участвовавших в эксперименте

\begin{tabular}{|l|c|c|}
\hline \multirow{2}{*}{\multicolumn{1}{|c|}{ Сустав }} & \multicolumn{2}{|c|}{ Количество травм } \\
\cline { 2 - 3 } & $\begin{array}{c}\text { за год до } \\
\text { эксперимента }\end{array}$ & $\begin{array}{c}\text { в рамках } \\
\text { эксперимента }\end{array}$ \\
\hline Коленный & 27 & 21 \\
\hline Голеностопный & 40 & 36 \\
\hline Локтевой & 24 & 17 \\
\hline Запястный & 18 & 12 \\
\hline Итого: & 109 & 86 \\
\hline
\end{tabular}

исследуемых теннисистов определялся четырьмя областями суставов: коленный, голеностопный, локтевой и запястный (табл. 2).

Результаты внедрения в учебно-тренировочный процесс стретчинговой программы показали, что за год тренировочных занятий теннисисты получили на 21,1 \% меньше травм, чем в предыдущий, когда экспериментальная методика еще не была апробирована в системе спортивной подготовки теннисистов.

Основные выводы и перспективы дальнейших исследований. Таким образом, можно утверждать, что разработанная методика с успехом может быть применена в системе учебно-тренировочных занятий теннисистов. Целенаправленное использование на тренировках стретч-упражнений способствует снижению уровня травматизма у спортсменов.

\section{Литература}

1. Алтер М. Дж. Наука о гибкости / М. Дж. Алтер. К.: Олимп. лит., 2001. - 424 с.

2. Дембо А. Г. Врачебный контроль в спорте / А. Г. Дембо. - М.: Медицина, 1988. - 124 с.

3. Дубровский В. И. Реабилитация в спорте / В. И. Дубровский. - М.: Физкультура и спорт, 2004. - 250 с.

4. ЖураљлеВа А. И. Спортивная медицина и лечебная фризкультура / А. И. Журавлева, Н. Д. Граевская. - М.: Медицина, 1999. - 266 с.

5. ЗуеВ Е. И. Волшебная сила растяжки / Е. И. Зуев. [2-е изд.]. - М.: Сов. спорт, 1993. - 64 с.

6. Планида Е. В. Влияние комплексов стретч-упражнений на функцциональное состояние квалифицированных баскетболистов: дис. ... канд. биол. наук / Е. В. Планида. Минск, 2006. - 180 с.

7. Смирнов В. М. Физиология фризического воспитания и спорта: учеб. для студентов сред. и высш. учеб. заведений / В. М. Смирнов, В. И. Дубровский. - М.: ВЛАДОС-ПРЕСС, 2002. -608 с.

8. СпортиЗная медицина: учеб. пособие для мед. вузов / под ред. В. А. Епифанова. - М.: ГЭОТАР-Медиа, 2006. $336 \mathrm{c}$.

9. ЮмашеВ Г. С. Оперативная травматология и реабилитация больных с повреждением опорно-двигательного аппарата / Г. С. Юмашев, В. А. Епифанов. - М.: Медицина, 1983. -383 c.

10. ЯкоВенко В. Стретчинг: как помирить «антагонистов» / В. Яковенко // Теннис +. - 2000. - № 9. - С. 12-13.
Дальнейшие исследования предполагают усовершенствование этой методики в плане ее индивидуализации с учетом повышения спортивного мастерства теннисистов. К тому же, разработка проблемы профилактики травматизма спортсменов возможна и перспективна для дальнейшего исследования нетрадиционных для спорта средств фритнеса, позволяющих совершенствовать процесс спортивной подготовки.

Положительные результаты, полученные в ходе работы, дают нам возможность рекомендовать тренерам разных видов спорта внедрять стретч-упражнения в процесс своих тренировочных занятий, как в подготовительную часть, так и заключительную в соответствии с поставленными задачами.

Стретчинг рекомендуется использовать не только при подготовке спортсменов. Такие упражнения дают большой оздоровительный эффект, поэтому его полезно включать в занятия оздоровительной и лечебной фризической культурой, как для расширения двигательного потенциала занимающихся, так и для исправления каких-либо отклонений в фризическом и фризиологическом развитии.

Методику применения стретчинга в занятиях физической культурой и спортом рекомендуется внести в состав программ учреждений по повышению квалификации учителей и тренеров.

\section{References}

1. Alter M. J. Science of Flexibility /M. J. Alter. - Kiev: Olimpiijskaya literature, 2001. - $424 \mathrm{p}$.

2. Dembo A. G. Vrachebnyi control' v sporte / A. G. Dembo. - Moscow: Medicina, 1998. - 124 p.

3. Dubrovskij V. I. Reabilitacija v sporte / V. I. Dubrovskij. - Moscow: Fizkul'tura i sport, 2004. -250 p.

4. Zhuravliova A. I. Sportivnaja medicina I lechebnaja fizcul'tura / A. I. Zhuravliova, N. D. Graevskaja. - Moscow: Medicina, 1999. - $266 \mathrm{p}$.

5. Zuev E. I. Volshebnaja sila rastjazhki / E. I. Zuev. 2-e izd. - Moscow: Sovetscij sport, 1993. - 64 p.

6. Planida E. V. Vlijanie kompleksov stretch-uprazhnenij na funkcional'noe sostojanie kvalificirovannyh basketbolistov: dis. ... kand. boil. nauk / E. V. Planida. - Minsk, 2006. $180 \mathrm{p}$.

7. Smirnov V. M. Fiziologija fizicheskogo vospitanija i sporta: Ucheb. dlja studentov i vyssh. zavedenij / V. M. Smirnov, V. I. Dubrivskij. - Moscow: VLADOS-PRES, 2002. -608 p.

8. Sportivnaja medicina: Ucheb. Posobie dlja med vuzov / Ed. V. A. Epifanov. - Moscow: GEOTAR-Media, 2006. $336 \mathrm{p}$.

9. Iumashev G. S. Operativnaja travmatologia I reabilitacia bol'nyh s povrezhedeniem oporno-dvigatel'nogo apparata / G. S. lumashev, V. A. Epifanov. - Moscow: Medicina, 1983. - 383 p.

10. Jakovenko V. Stretching: kak pomirit' «antagonistov» / V. Jakovenko // Tennis +. -2000. - N 9. - P. 12-13. 